\title{
CIVIL LIABILITY FOR NEGLIGENCE: AN ANALYSIS OF CYBERBULLYING POLICIES IN SOUTH AUSTRALIAN SCHOOLS
}

\author{
PETA SPYROU.
}

Cyberbullying is a form of covert bullying that affects the lives of young people and adults alike. Empirical evidence suggesting that the effects of cyberbullying may lead to protracted mental harm highlights the need for schools to take a proactive stance against this form of bullying. This article looks specifically at the effectiveness of the anti-bullying policies implemented by South Australian school authorities in order to comply with their legal duty of care in negligence. Part I introduces the topic of cyberbullying, while Part II explains a school's legal liability for instances of cyberbullying and identifies the requisite need for anti-bullying polices. In addition, Part III highlights the need for a multifaceted approach to reduce the occurrence of cyberbullying that recognises the important roles played by parents and student bystanders. This section concludes by providing specific recommendations on how anti-bullying policies should be implemented. The article argues that while school authorities may bear legal liability for instances of cyberbullying, schools cannot effectively implement anti-bullying policies without forming a partnership with the whole school community.

\section{CONTENTS}

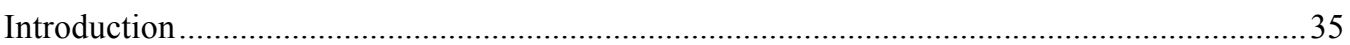

II Schools' Liability

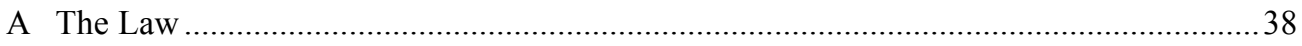

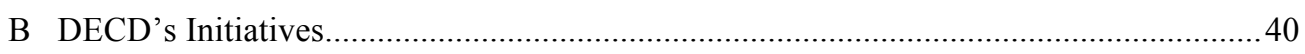

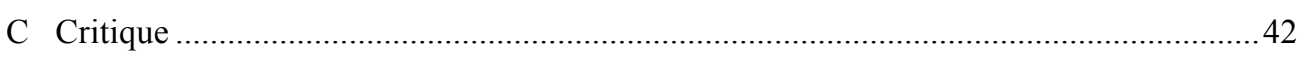

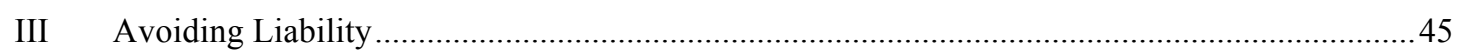

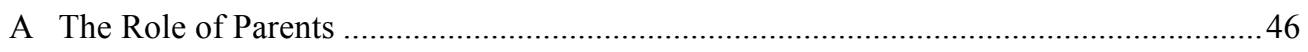

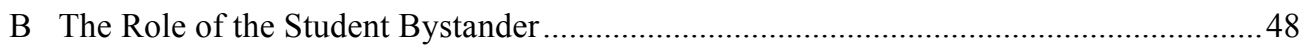

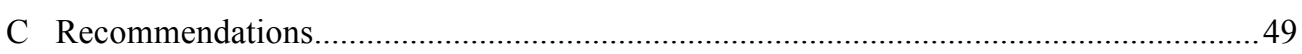

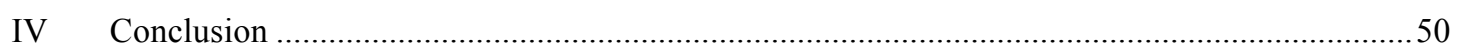

LLB student, School of Law, University of South Australia. 


\section{INTRODUCTION}

Society's increased dependence on Information and Communication Technologies ('ICTs') has provided bullies with a new platform upon which to target victims. Because life in the digital age has infiltrated the realm of cyberspace, bullying is no longer confined to face-to-face altercations in the schoolyard. Cyberbullying is a worrying phenomenon because it can occur at any time and can lead to devastating consequences. It can manifest in a variety of different forms, ${ }^{1}$ and this, combined with the absence of a universally accepted definition of cyberbullying, makes it difficult to find reliable data on the prevalence of cyberbullying in Australia. However, a recent estimate suggests that approximately 20 per cent of students aged 8-17 experience cyberbullying each year. ${ }^{2}$ The impact that cyberbullying can have on school students is a matter of particular concern because these 'digital natives ${ }^{3}$ regularly employ ICTs and use technology to form their social identities. Furthermore, with the availability of technology increasing as a result of school initiatives like 'bring your own device' ${ }^{4}$ and 'flipped learning' classes, ${ }^{5}$ this form of misconduct is not confined to regular school hours.

Although there is no universally accepted definition of cyberbullying, Campbell, Butler and Kift have adopted Bill Besley's definition of cyberbullying as:

The use of information and communication technologies such as e-mail, cell phone and pager text messages, instant messaging (IM), defamatory personal Web sites, and defamatory online personal polling Web sites, to support

I Colette Langos, 'Regulating Cyberbullying: A South Australian Perspective'16 (1) (2014) Flinders Law Journal 73, 73.

2 Ian Katz et al, Research on Youth Exposure to, and Management of, Cyberbullying Incidents in Australia: Synthesis Report (SPRC Report 16/2014). Sydney: Social Policy Research Centre, UNSW Australia.

3 Marc Prensky, 'Digital Natives, Digital Immigrants' (2001) 9(5) On the Horizon 1, 1 uses the term 'digital natives' to point to the fact that 'Our students today are all 'native speakers' of the digital language of computers, video games and the Internet.'

4 Fran Foo, 'Schools Make a Move to BYOD', The Australian (online), 07 May 2013 $<$ http://www.theaustralian.com.au/business/technology/schools-make-a-move-tobyod/story-e6frganx-1226636277661>.

5 Sean Gallagher, 'MOOC Means More Time for Different Types of Learning', The Australian (online), 20 March 2013 <http://www.theaustralian.com.au/highereducation/opinion/mooc-means-more-time-for-different-types-of-learning/story-e6frgcko1226600961476>. 
deliberate, repeated, and hostile behaviour by an individual or group, that is intended to harm others. ${ }^{6}$

Cyberbullying is far reaching and can affect victims both on a direct personal basis via instant messaging, emails and chat-rooms; and indirectly through public forums such as Facebook, Myspace, Tumblr and Twitter. ${ }^{7}$

Besley's definition points up a fundamental issue associated with cyberbullying, namely, the use of one of the tools most valued by young people (ie, technology) as the means of victimising them. Scholarly research has explained that victims are unlikely to come forward and report cyberbullying incidents for fear of losing access to the technology. ${ }^{8}$ This underreporting therefore makes it difficult for teachers and parents to respond. ${ }^{9}$ Moreover, the potential 'digital divide' between the parent, who may seek to protect their child by restricting access to ICTs, and the child, whose social identity is intimately connected with their digital identity, exacerbates this detection issue. ${ }^{10}$

Another significant feature of cyberbullying that leads to difficulties in detection is its "covert" mean 'a less direct form of hidden bullying', students perceive this concept as encompassing 'any form of bullying that is hidden' and 'not seen by adults'. ${ }^{12}$ The Australian Covert Bullying Prevalence Study conducted in 2009 explains that this form of covert bullying not only exacerbates the harm

6 Marilyn Campbell, Des Butler and Sally Kift, 'A School's Duty to Provide a Safe Learning Environment: Does this Include Cyberbullying?' (2008) 13 (2) Australia and New Zealand Journal of Law and Education, 21, citing Bill Belsey, Always On? Always Aware (17 January 2007) Cyberbullying <http://www.cyberbullying.ca $>$.

7 Colette Langos, 'Which Laws Can Apply to Cyberbullying?' (2013) 35(10) The Bulletin 38, 38 .

8 Donna Cross et al, Australian Covert Bullying Prevalence Study, Research Report for Department of Education, Employment and Workplace Relations (2009) xxv.

9 Given the fact that instances of cyber-victimisation may be difficult to identify, the Commonwealth Office of the Children's eSafety Commissioner's website alerts parents, school staff and student bystanders to the fact that evidence may include mood swings, changes to physical health, friendships, sleeping patterns and avoidance of school and school-based activities, see eg, 'Cyberbullying - information for parents':

$<$ https://esafety.gov.au/esafety-information/esafety-issues/cyberbullying/cyberbullyinginformation-for-parents $>$.

10 Elly Robinson, 'Parental Involvement in Preventing and Responding to Cyberbullying' (2013) 92 Australian Institute of Family Studies 71, 73.

11 Donna Cross et al, above n 8,12

12 Ibid xxi. 
caused to victims, but also makes it less likely that the bully will be caught. ${ }^{13}$ Unlike the case of physical bullying, which requires an element of personal daring, cyberbullying allows a coward to inflict harm indirectly and on a repeated basis. This means that it is 'difficult for teachers and school administrators to prevent or stop'. ${ }^{14}$

Even though they are difficult to detect, incidents of cyberbullying can attract both criminal and civil actions designed to hold the perpetrator to account. Cyberbullying will amount to a crime if the conduct is so serious that it constitutes threatening, harassing, intimidating, assaulting, stalking or criminal defamation. ${ }^{15}$ Alternatively, a civil action may be brought against the tortfeasor(s) under the tort of assault. ${ }^{16}$ An additional civil action in negligence may also be initiated against the school authority for breaching its duty of care if it fails to respond to bullying in an appropriate manner or fail to take appropriate preventative steps. Consequently, Australian schools have attempted to address the issue of cyberbullying by implementing 'Reasonable Use Agreements' and anti-bullying policies. ${ }^{17}$ In South Australia, schools are required by the Department for Education and Child Development (DECD) to ensure that these anti-bullying policies are effectively implemented.

Part II of this article examines a school's duty of care in cases of cyberbullying and explains how a school may open itself up to civil liability where bullying policies are ineffective. It provides a novel insight into the processes and procedures that the South Australian DECD has recently implemented in an attempt to better support schools in managing bullying and cyberbullying. Part II also identifies deficiencies in both the internal and external review process and makes suggestions for improvements. Part III looks beyond the issues of school liability by highlighting the need for a multifaceted approach to reducing the occurrence of cyberbullying. It explores the role that parents and bystanders play in the management of cyberbullying and highlights the advantages of a holistic approach involving parents, students, teachers and the Department itself. Part III also provides

13 Ibid xxvi.

14 Australian Institute of Criminology, 'Covert and Cyberbullying' (2011) 9 Research and Practice Tipsheet 1, citing Peter K Smith et al, 'Cyberbullying: Its Nature and Impact in Secondary School Pupils’ (2008) 49(4) The Journal of Child Psychology 376, 381.

15 Langos, above $\mathrm{n} 7$.

16 Oyston v St Patrick's College [2013] NSWCA 135. This applies whether or not the victim's parents had knowledge of the incident.

17 Government of South Australia Department for Education and Child Development, Safer DECD Schools, (1 January 2011) Australian Policy Online < http://www.saasso.asn.au/wpcontent/uploads/2012/11/Safer-DECD-schools.pdf>. 
recommendations aimed at encouraging school authorities to form partnerships with important stakeholders and to ensure that their policies are effectively implemented. The article concludes in Part IV that ultimately, to reduce exposure to liability for instances of cyberbullying, schools need a practical approach in educating the wider school community about the school's 'Reasonable Use Agreements' for the use of ICTs.

\section{SCHOOLS' LIABILITY}

\section{A The Law}

At common law, school authorities owe a non-delegable duty of care to their students and they may also be vicariously liable for any individual teacher's breach of their personal duty of care owed to the student. These duties were initially confined to incidents that occurred on campus, ${ }^{18}$ however, Sheller JA in Trustees of the Roman Catholic Church for the Diocese of Bathurst $v$ Koffman, ${ }^{19}$ determined that the basis for a school's duty is dependent upon the relationship between the teacher and their pupil. ${ }^{20}$ This case illustrated that, depending on the relationship, a school authority may owe a duty of care to students for bullying incidents that occur beyond the school gates and outside school hours. ${ }^{21}$ The law also imposes an obligation on school authorities to ensure that preventative measures (eg, anti-bullying policies) are effectively implemented to deal with bullying incidents in an appropriate and prudent manner. ${ }^{22}$

In South Australia, the scope of the duty is limited under sections 31 and 32 of the Civil Liability Act 1936 (SA) ('CLA'). These sections limit the standard of care owed by school authorities to the actions that a 'reasonable' school authority would have taken, in light of all the information that the school had or ought reasonably to have had in the particular circumstances. A relevant consideration in assessing the breach of this duty is the existence of professional or customary standards. ${ }^{23} \mathrm{~A}$ successful negligence claim is contingent upon proof that the victim has suffered from a 'recognisable

Commonwealth of Australia v Introvigne (1982) 150 CLR 258; NSW v Lepore (2003) 212 CLR 511.

19 (1996) Aust Torts Reports 81-399, 63,597.

20 Ibid 63,596, (Sheller JA citing Stephen J in Geyer v Downs (1977) 138 CLR 91, 93-94).

${ }^{21}$ Trustees of Roman Catholic Church for the Diocese of Bathurst v Koffman (1996) Aust Torts Reports 81-399.

22 Oyston v St Patrick's College [2013] NSWCA 135.

23. Mercer $v$ Commissioner for Road Transport and Tramways (NSW) (1936) 56 CLR 580. 
psychiatric illness ${ }^{24}$ as a result of the breach of duty. Furthermore, a defendant may rely on s 41 of the CLA as a defence, by claiming that the school 'acted in a manner that (at the time the service was provided) was widely accepted in Australia by members of the same profession as competent professional practice'. ${ }^{25}$ Therefore, a student who has been subjected to cyberbullying and who has developed a recognised psychiatric illness could bring a successful negligence claim against their school in situations where the teacher or school authority failed to act in accordance either with the responses accepted by the education profession as appropriate, or with the way that a reasonable person in the teacher's position would have acted in that situation.

In a letter dated 8 May 2009, the then Chief Executive of the DECD, Chris Robinson, advised principals and regional directors that, under regulations 40 and 41 of the Education Regulations 1997, they had the capacity to respond to incidents of cyberbullying and electronic crime regardless of whether the offence occurred 'outside of school hours or off site' ${ }^{26}$ Currently, the power of schools to discipline students is governed by the Education Regulations 2012, issued under the Education Act 1972 (SA). Accordingly, regulations 44,45 and 46 enable a school principal to punish students by way of suspension, exclusion or expulsion, if the principal is of the reasonable belief that a student has 'acted in a manner that threatens the safety or well-being of a student or member of staff of, or other person associated with, the school (including by sexually harassing, racially vilifying, verbally abusing or bullying that person) ${ }^{, 27}$ The wording of these regulations in conjunction with the letter mentioned above, indicates that school authorities have the authority to discipline students for cyberbullying incidents that transpire both on and off campus and beyond the hours of a school day. ${ }^{28}$

24 See Civil Liability Act 1936 (SA) s 53(2).

25 A recent NSW case has explained that the similarly worded provision in s $5 \mathrm{O}$ of the Civil Liability Act 2002 (NSW) functions as a defence: Dobler v Halverson [2007] NSWCA 335, [54]-[61].

26 Memo DECS 09/3677 'The action principals can take for incidences of cyberbullying or electronic crime' from Chris Robinson (Chief Executive DECS, now DECD) to Principals and Regional Directors, 8 May 2009, copy on file with the author.

27 See Education Regulations 2012 (SA) regs 44(1)(b), 45(1)(b) and 46(1)(b).

28 The ability of principals to suspend students for incidents of cyberbullying occurring outside school hours and off campus was recently invoked by the principal of the Adelaide High School: see Natalie Whiting, 'Adelaide High School students suspended over abusive Facebook messages sent to feminist writer Clementine Ford', $A B C$ News (online), 24 June 2015: 
In an attempt to respond to the duty to combat cyberbullying vigilantly via the implementation of effective anti-bullying policies, the DECD has proposed that all incidents of inappropriate cyber practices need to be treated as behaviour management issues, and dealt with by relevant school policy, even if the incident occurs outside school hours. ${ }^{29}$ Responding to a bullying incident that made media headlines in $2011,{ }^{30}$ the Hon Jay Weatherill MP commissioned a review headed by Bill Cossey ('Cossey Review') to evaluate the existing policies on incidents of school bullying and violence. In response to the Cossey Review's findings, and to ensure that every South Australian school complied with the National Safe Schools Framework, the DECD implemented the recommendations made in the Cossey Review. This article will focus only on one particular recommendation, which led to the creation of a 'regional director' to 'verify anti-bullying policies and report on compliance levels'. 31

\section{B DECD's Initiatives ${ }^{32}$}

In November 2014, the DECD implemented the Improvement and Accountability Policy ('IAP'), which imposes a very broad responsibility on principals and staff to:

- Use data and evidence to regularly monitor student achievement and progress over time;

- Develop and implement a School Improvement Plan (SIP) for schools that align with the DECD Strategic Plan and includes planned actions based on recommendations from external review processes;

- Plan and implement evidence based intervention strategies addressing identified targets, outcomes, and learning needs that are designed to maximise learner outcomes and achievement;

- Conduct an annual self-review;

$<$ http://www.abc.net.au/news/2015-06-24/adelaide-high-school-students-suspendedviolence-women-messages/6570078>.

29 Memo DECS 09/3677, above n 26.

30 Sean Fewster, 'Craigmore High School Facebook Bully Ends up in Elizabeth Magistrates Court', news.com.au (online) 7 June $2011<$ http://www.news.com.au/national/craigmorehigh-school-facebook-bully-ends-up-in-elizabeth-magistrates-court/story-e6frfkp9$1226070961704>$.

31 Government of South Australia Department for Education and Child Development, above $\mathrm{n}$ 17.

32 The author would like to acknowledge Susan Cameron, Director Review Improvement and Accountability, for her insightful comments in relation to the following section of the article. 
- Publish an Annual Report that describes the site/school's performance, the self-review processes, and SIP improvement and accountability outcomes; and

- ... Participate in an external school review (ESR) process at least every four years, and priority reviews as required. ${ }^{33}$

The broader IAP scheme incorporated the recommendation made by the Cossey Review to create a position responsible for overseeing the implementation of anti-bullying policies in each school. There are currently 20 education directors (previously known as 'regional directors') who have the responsibility to certify that all State schools have 'a high performing system that improves the educational attainment and wellbeing of South Australia's children and young people'. ${ }^{34}$ Each education director has ensured that every State school currently has an anti-bullying policy, which has been signed off by the school's governing council, and is accessible via the school's website. However, the responsibility for compliance reporting now vests with the IAP, not the education director. The IAP 'outlines the key features of the DECD approach to lifting the attainment of learning and development outcomes though continuous review, improvement and accountability'. ${ }^{35}$ The IAP's framework has increased the responsibility of principals to conduct an internal assessment of whether every policy aspect is complied with. The review process commenced early in 2015. Principals are required to conduct these rigorous on-going self-review processes to 'monitor and evaluate progress towards the National Quality Standard or DECD Standard of Educational Achievement, and the attainment of identified targets and priority outcomes'. ${ }^{36}$

Once the principal has signed off on the school's compliance levels, a review panel conducts an external audit. The review panel comprises a Review Officer, as well as at least one trained Review Principal. Currently, these external reviews are to occur on a four-yearly basis, and involve an audit of one aspect of the Department's standard policy statement. The topic for audit is determined by the director making a recommendation to the Executive. Once approval is granted, and the principal's internal review indicates complete policy compliance, the review panel is theoretically responsible to report only on the compliance of that policy element. This auditing process is

33 Department for Education and Child Development, 'DECD Improvement and Accountability Policy' (2014) 1-9, 4.

34 Department for Education and Child Development, 'Introduction: Building a High Performing System' (2014) 2.

35 Department for Education and Child Development, above n 33.

36 Ibid 5. 
completed by way of a checklist, looking for evidence of the particular policy. If, however, a principal has indicated an area of non or partial compliance, the review panel conducts an initial report to determine the severity of the problem and reports on the extent of compliance for the whole policy.

Following the external review, a report is generated and provided to the school's principal. If the report's key findings indicate non-compliance, the principal has a responsibility to liaise with their designated education director to formulate an action plan to ensure that the policies are implemented effectively and compliance is met. Once the principal, the chairperson of the governing council, and the education director receive the external review report, the principal has four weeks to publish it on the school's website. ${ }^{37}$ Principals are also required to contact their education director to report severe cases of bullying. In turn, the education director has the role of providing assistance in determining the most appropriate response.

Another initiative employed by DECD schools and other non-government schools across Australia, relates to ICT Security Policies. ${ }^{38}$ These policies

must be in the form of a written agreement, signed by staff, students and/or their parents/guardians, outlining the terms and conditions of use of the DECD ICT facilities, and of online behaviour and access privileges, as well as consequences of non-compliance. ${ }^{39}$

The Department has indicated that these forms of agreement should: outline online safety mechanisms, detail the legal ramifications for misuse of ICTs; impose a responsibility on parents to oversee their child's use of ICTs; and force older students to 'take responsibility for their own actions by agreeing to use DECD ICT facilities in a responsible manner' ${ }^{40}$

\section{Critique}

Although these initiatives aimed at ensuring the effective implementation of anti-bullying policies are a welcome development, the current policies present five areas of concern. First, it is important to note that the four-yearly external appraisal (the proposed regularity of the review) is too infrequent.

37 Ibid 7.

38 Department for Education and Child Development, DECD Standard - Acceptable Use Policies for Schools, Preschools and Children's Services Sites $<$ http://decd.sa.gov.au/docs/documents/1/DecdStandardAcceptableUse.pdf $>$.

39 Ibid.

40 Department for Education and Child Development, above n 33, 7. 
Considering that the estimated prevalence of cyberbullying is around 20 per cent for students aged 8-17 over a 12 -month period, ${ }^{41}$ it can be inferred that the efficacy of these anti-bullying policies, which have been in existence since 2006, is questionable. A yearly review ought to be considered. Furthermore, the DECD is relying on the ability of school principals to identify issues of compliance. Ensuring that every principal possesses the requisite credentials to identify areas of non-compliance would guarantee that they have the requisite knowledge about cyberbullying to identify potential compliance issues. Hinduja and Patchin explain the importance of school administrators taking time to educate and inform themselves about the issues associated with cyberbullying and online aggression, and explain the need for administrators to 'pass important information along to teachers and counsellors' ${ }^{42}$ They also note the need to define the concept of cyberbullying clearly and to conduct anonymous surveys of staff and students to determine 'the current state of online behaviours'. ${ }^{43}$ This would also aid in assessing compliance with anti-bullying policies.

A second problem arises because the South Australian IAP, noted above, casts a very wide responsibility on principals and reviewers that goes far beyond bullying, and is designed to 'maximise every student's learning, ${ }^{44}$ Initially, the Cossey Review envisaged having one dedicated position that would be tasked with the responsibility of implementing anti-bullying polices and also reporting on compliance. Under the IAP, however, that position does not exist, because the IAP subsumes the responsibility into a much wider reporting structure. The consequent loss of focus on bullying and the safety of students is illustrated by the fact that the term bullying is not specifically mentioned in the IAP. Principals were encouraged to audit their procedures in the 2011 'Safer DECD Schools' document. ${ }^{45}$ To assist in this process, the DECD created an 'anti-bullying policy audit checklist' that was 'based on meeting the recommended actions under 'Element 3: Policies and Procedures' of the National Safe Schools Framework', ${ }^{46}$ but this checklist does not mandate a separate reporting system. It would be more manageable and effective if, in addition to the IAP general review process, the DECD

${ }^{41} \quad$ Katz et al, above n 2.

42 Sameer Hinduja and Justin Patchin, Bullying Beyond the School Yard (Corwin Press, 2009) 131.

43 Ibid 130.

44 See text accompanying $n$ 33, above.

45 The author would like to acknowledge Susan Cameron, Director Review Improvement and Accountability, for her insightful comments.

46 'Anti-bullying Policy - School Audit Checklist and Support Information' $<$ http://www.saasso.asn.au/wp-content/uploads/2015/03/draft_for_web_anti_bullyin.pdf $>$. 
created a review position that could focus solely on anti-bullying policy compliance as recommended by the Cossey Review.

The third problem is that the DECD requires that a school's anti-bullying policy be easily accessible online. My investigation of websites of four primary schools and four high schools (one each from the northern, southern, eastern and western regions of South Australia), revealed that access to these policies varied. Some schools featured their policies in prominent, nonambiguous locations, under tabs such as "reports and/or policies" ${ }^{47}$ or 'student care'. ${ }^{48}$ Others featured their anti-bullying policies on their main page. ${ }^{49}$ Some schools also featured a separate tab for key information on cyberbullying, such as helplines for parents and caregivers, as well as having a separate tab for their anti-bullying policy. ${ }^{50}$ Anti-bullying policies that were located on the school's main page were the easiest to find, but one school's policy could be found only by using the search term 'policy' on the website's search ribbon (after searches for 'cyberbullying', 'anti-bullying' and 'bullying' failed). ${ }^{51}$ Consequently, I recommend that the DECD should compel schools to feature anti-bullying policies on the home page of every website, together with the external review(s) that will eventually be generated post internal review. This would ensure easy accessibility, promote the importance of anti-bullying initiatives and achieve a level of transparency in schools.

The fourth problem arises from the requirement for students and parents to sign the use agreements. A student's parent or caregiver is required to sign the DECD's 'Reasonable Use Policy' or 'Cyber Safety Use Agreement'. However, a mere signature may not demonstrate a sufficient understanding of the school's acceptable use plan. This may result from a lack of understanding about technology or from a parent or caregiver simply signing without reading the policy for the sake of convenience. Either way, this problem can be resolved by schools creating a computer or phone 'app' which provides instant, easy access to the components of the policy in plain English; or by running an information night that outlines the parameters of the policy with a clear explanation of each section.

\footnotetext{
7 School A (northern suburbs, high school).

48 School B (southern suburbs, high school).

49 School C (southeast suburbs, primary school and preschool).

50 School D (northern suburbs, primary school).

51 School E (western suburbs, high school).
} 
The fifth problem arises out of the covert nature of cyberbullying. Because the bullying is generally indirect, not all incidents are observed or reported, and given that the IAP is evidence based, compliance reporting results may be inaccurate. This limitation could be addressed by investigating alternative initiatives that focus on preventative measures that can better support young people in instances of cyberbullying.

This section has illustrated the important role that school authorities play in preventing and dealing with cyberbullying. However, schools cannot effectively respond to such incidents without the support of parents and student bystanders. To ensure that school authorities have an effective relationship with parents, Hinduja and Patchin recommend that schools 'designate one or more staff members to serve as trustees. ${ }^{52}$ These trustees can be either student counsellors or teachers, so long as they have specific training to deal with cyberbullying and other forms of online aggression. ${ }^{53}$ This initiative would arguably ensure that cyberbullying incidents are prudently dealt with by allowing parents to direct their questions or concerns to a designated staff member. The trustees could also assist the principal in reporting on compliance levels and ensuring that anti-bullying policies are adhered to properly.

Part III will build upon the existing knowledge base by considering how schools can avoid liability through forming a partnership with parents and students to respond to cyberbullying in a comprehensive manner.

\section{AVOIDING LIABILITY}

Dwyer and Esteal note the influential role that parents play in preventing cyberbullying. They recommend that all schools should follow the approach implemented by South Australian Government schools in adopting 'Cyber Safety Use Agreements' in an attempt to discharge their duty of care owed to students. This DECD initiative stipulates that:

Until the parent/s return a signed 'Use Agreement Form,' students are not permitted to use the school information and communications technology ('ICT') equipment. Parents and students must agree that the students will, inter alia, 'use the Internet, e-mail, mobile phones or any ICT equipment only for positive purposes, not to ... bully, harass, or in any way harm anyone else...' and will report any

$52 \quad$ Hinduja and Patchin, above n 42, 165.

53 Ibid 58. 
instances of cyber bullying, suspected or otherwise to the school. ${ }^{54}$

Therefore, it becomes clear that a school's duty requires an active approach that goes beyond simply having a policy. The school is also obliged to do what is reasonable to ensure that anti-bullying policies are followed. ${ }^{55}$ It is arguable that one of the necessary steps that a school should take is to go beyond a principal's obligation of merely reporting on policy compliance to the education director. If a school is sincere about responding to the risk of harm posed by cyberbullying, the school needs to approach the issue in a proactive manner and engage expert opinion in the education of parents, students and the wider school community.

Scholars have suggested that one effective means of changing perceptions is to shift student norms about cyberbullying, bullying and aggression generally. ${ }^{56}$ Willard argues that a shift against student norms condoning or tolerating cyberbullying is one of the most effective strategies in reducing victimisation. ${ }^{57}$ She highlights the importance of preventing desensitisation to cyberbullying and eradicating the perception that it is 'perfectly appropriate to send a hurtful message because everyone does it'. ${ }^{58}$ Thus, parental and school encouragement towards positive social norms enables peers to constructively diminish the impact that peer pressure plays in the occurrence of negative behaviour. ${ }^{59}$

\section{A The Role of Parents}

With the availability of technology increasing through school initiatives such as 'bring your own device" ${ }^{60}$ and 'flipped learning classes', ${ }^{61}$ cyberbullying is becoming increasingly prevalent outside the school gates. This factor, in

54 Amy Dwyer and Patricia Esteal, 'Cyberbullying in Australian Schools: The Question of Negligence and Liability’ (2013) 38(2) Alternative Law Journal 92, 95.

55 Oyston v St Patrick's College [2013] NSWCA 135.

56 Nancy Willard, Cyber Savvy: Embracing Digital Safety and Civility (Corwin, 2012) 8.

57 Ibid.

58 Ibid 26.

59 Colette Langos, Cyberbullying, Associated Harm and the Criminal Law, (PhD Thesis, The University of South Australia, 2013), 263-264.

60 Paul Cleary, 'Tablets can Become a Bitter Pill', The Australian (online), 29 January 2015 $<$ http://www.theaustralian.com.au/national-affairs/education/tablets-can-become-a-bitterpill/story-fn59nlz9-1227200056844>.

61 Sean Gallagher, 'MOOC Means More Time for Different Types of Learning', The Australian (online), 20 March 2013 <http://www.theaustralian.com.au/highereducation/opinion/mooc-means-more-time-for-different-types-of-learning/story-e6frgcko$1226600961476>$. 
conjunction with cyberbullying's covert nature, underscores the importance of parental intervention. Empirical evidence suggests that adolescents are unlikely to disclose cyberbullying incidents to adults out of fear of having their access to ICTs restricted. ${ }^{62}$ This response has been criticised by academics and researchers alike, arguing that 'this is the least appropriate course of action. ${ }^{63}$ Essentially, due to the 'digital divide' between parents and society's 'digital natives', parents may not understand the importance that their children place on their access to and use of technology. ${ }^{64}$ Consequently, there is a need for schools not only to educate students, but also to extend education to parents. Schools can play an instrumental role, first by keeping parents up to date with changes to the ever evolving 'bullying matrix', and also by offering them alternative strategies for responding to cyberbullying that do not restrict a child's use of technology. ${ }^{65}$ Regular information nights, workshops and seminars presented by experts in the cyberbullying field could achieve this goal by plainly emphasising that restricting the use of ICTs will not stop this type of indirect bullying.

Robinson also details the critical role that parents have from the time their children first use technology. Parents should ensure that their children are using ICTs in a safe and responsible way by monitoring their internet usage. ${ }^{66}$ Moreover, Robinson emphasises the importance of encouraging parents to establish good communication by partnering with their child's school to 'report the incident(s) to the school as soon as possible and ask for and accept help from the school, no matter whether the child is being bullied or has been a witness to bullying. ${ }^{67}$ This recommendation should subsequently be extended to encourage parents to report any bullying incident, cyberbullying or other, even if the parent has knowledge that their child is the perpetrator. Action of this nature would demonstrate an unequivocal attitude against cyberbullying. Parental involvement may also be instrumental in reducing the occurrence of cyberbullying by playing a significant role in detecting and disclosing incidents to the school, as well as reinforcing a repertoire of positive cyber practices. ${ }^{68}$ Furthermore, schools could develop regular programs and strategies aimed at educating the whole school community about the complexities of cyberbullying, and at ensuring that every parent is

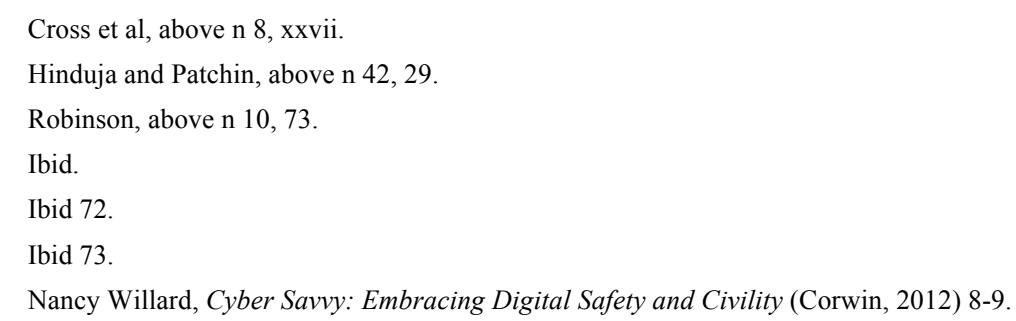


familiar with the school's 'Reasonable Use Agreements', 'Cyber Safety Use Agreements' and the consequences if such polices are not adhered to. A UK study showed that the most effective response against cyberbullying involved a continued relationship between families and the school. ${ }^{69}$ Parents should therefore be encouraged to take an active role in their child's life by discussing and devising response mechanisms to cyberbullying, outlining good cyber-citizenship behaviours and defining negative online behaviours. ${ }^{70}$

By facilitating information nights or workshops, schools have an opportunity to contextualise the issue of cyberbullying for parents and outline the importance of parents taking an active approach in creating an online use plan and monitoring their child's internet profile. In addition, a school may highlight strategies for dealing with cyberbullying, such as encouraging bystanders to come forward. ${ }^{71}$ Schools should also alert parents about the government websites aimed at providing both parental and student support if a cyberbullying incident should surface. Such resources could include 'Bullying No Way' ${ }^{72}$ and 'Cybersmart'. ${ }^{73}$ Schools could also use these forums to inform parents that most social networking sites have a minimum usage age of 13 years, therefore motivating parents to deter children under 13 years of age from using these sites. ${ }^{74}$

\section{B The Role of the Student Bystander}

Hinduja and Patchin allude to the important role that bystanders play if they witness incidents of indirect cyber-victimisation. ${ }^{75}$ However, scholars admit that these bystanders are placed in a difficult position because bystanders:

[G]enerally do not want to get involved because of the hassle and problems they fear it might bring upon them, yet they often recognise that what they are seeing is not right and should stand up. ${ }^{76}$

As a result, it is essential that schools and parents encourage the moral conscience of student bystanders by educating students about the positive

\footnotetext{
${ }^{69}$ Office for Standards in Education, Children's Services and Skills, The Safe Use of New Technologies, (February 2010) $<$ http://dera.ioe.ac.uk/1098/1/The\%20safe\%20use\%20of\%20new\%20technologies.pdf $>$. 
role that they can play in creating a safe environment. ${ }^{77}$ The Australian Human Rights Commission supports this notion of motivating bystanders to act and notes that bystanders play an important role in reducing cyberbullying. ${ }^{78}$

The action of school authorities can be influential in encouraging student bystanders to come forward and report cyberbullying. Schools could set up an online reporting system that enables a witness to lodge an anonymous report to a staff member, outlining what they observed and providing photographic evidence where applicable. ${ }^{79}$ This initiative would circumvent the need for a student to confront the perpetrator face-to-face and may encourage more individuals to come forward. Importantly, however, Hinduja and Patchin observed that bystanders are more inclined to take a stance against bullying where they 'believe that positive outcomes will result from their effort. 80

\section{Recommendations}

To facilitate improvements to the efficiency of the DECD's initiatives in ensuring school authorities have effective anti-bullying policies and accurate compliance reporting procedures, it is paramount that a strong relationship exists between school authorities and DECD representatives (education director and members of the Review Panel). This partnership needs to focus on the process of evidence collection, and should include anonymously surveying the whole school community (including parents). Furthermore, a Government sponsored partnership should be formed between schools, behavioural-management experts and education directors, to work together to develop strategies aimed at educating the whole school community about this complex phenomenon.

Not only is the effectiveness of the DECD's review processes dependent upon nurturing relations between the Government and State schools, but also the partnerships between schools and parents. This can be achieved through various means, but depends on maintaining an open line of communication between parents and the school. Regular parental information nights and

\footnotetext{
77 Australian Human Rights Commission, Cyberbullying, Human Rights and Bystanders, Australian Human Rights Commission

$<$ https://bullying.humanrights.gov.au/sites/default/files/content/pdf/bullying/VHB_cyberbull ying.pdf $>$

78 Ibid.

79 Hinduja and Patchin, above n 42, 175.

$80 \quad$ Ibid 58.
} 
workshops that have a practical approach in promoting understanding of the school's 'Reasonable Use Agreements' or 'Cyber Safety Use Agreements' can assist in contextualising the issues associated with cyberbullying. Schools should also be encouraged to adopt strategies aimed at fostering positive student norms that support the participation of student bystanders. This in turn may reduce the occurrence of aggression initiated through peer pressure.

\section{CONCLUSION}

As the use of ICTs becomes increasingly prevalent in schools, the probability of misuse increases. Accordingly, it is imperative that schools mitigate the risk of liability by implementing effective anti-bullying and/or cyberbullying policies that optimise student wellbeing. This article has argued, however, that the mere existence of these policies is not enough to tackle cyberbullying and satisfy a school's duty of care. Rather, a multifaceted educational partnership that involves the whole school community is fundamental to ensuring that schools comply adequately with their duty to respond to the risk of harm posed by cyberbullying. First, school authorities need to educate parents, staff and students about this new bullying platform. This element arguably also requires government-sponsored information initiatives. Secondly, school authorities need to take reasonable steps to educate the whole school community about how the relevant anti-bullying policy, 'Reasonable Use Agreement' or 'Cyber Safety Use Agreement' works. It is important that each stakeholder is made aware of the requirements of these agreements because the whole school community needs to be involved in the cyberbullying conversation. To address problems associated with detection, parents, staff and students need to understand the importance of bringing cyberbullying incidents to the school's attention.

In light of this conclusion, the article has criticised the Department for Education and Child Development's 'Improvement and Accountability Policy' because it lacks the element of education and thereby fails to ensure the effective implementation of anti-cyberbullying policies. The policy unfortunately fails to emphasise the importance of the whole school's understanding of cyberbullying and an appreciation of how the relevant antibullying policy works. The article has also criticised the scope of responsibility imposed on the IAP Review Panel, and has argued that in overseeing all aspects of the National Framework, the IAP is not effectively focused on bullying in all of its forms and consequently, does not focus sufficiently on the issue of cyberbullying, which is a special form of bullying. 
The involvement of parents, staff and students could also increase the accuracy of the IAP's review process by allowing the Review Panel to obtain a holistic understanding of the prevalence of cyberbullying supported by reliable empirical data, eg, through the use of anonymous surveys. These initiatives would ensure that school authorities, education directors and the Review Panel could ascertain whether current policies are effective or ineffective.

The engagement of the whole school community is likely to reduce the exposure of a school to liability by making it difficult for a plaintiff to argue that the school authority failed to respond reasonably to the foreseeable risk of harm posed by cyberbullying. More importantly, whole of school involvement would also assist principals in providing for the well-being, welfare and development of students as required by the Education Regulations 2012 (SA). Specifically, it would support the Department's wider goal of providing a 'social and educational environment within the school favourable to learning, acceptable forms of behaviour and the development within students of self-control, self-discipline and a respect for other persons' ${ }^{81}$ Therefore, while school authorities may bear legal liability for cyberbullying, this article has endeavoured to show that schools cannot effectively implement anti-bullying policies without forming a partnership between parents, staff and students.

81 Education Regulations 2012 (SA) reg 42(1)(b)(iv). 